\title{
Addressing changed sexual functioning in cancer patients: A cross-sectional survey among Dutch oncology nurses
}

\author{
E.M. Krouwel ${ }^{\text {a, }}{ }^{*}$, M.P.J. Nicolai a , A.Q.M.J. van Steijn-van Tol ${ }^{\text {b }}$, H. Putter ${ }^{\text {c }}$, S. Osanto ${ }^{\text {b }}$, \\ R.C.M. Pelger ${ }^{a}$, H.W. Elzevier ${ }^{a}$ \\ a Department of Urology, Leiden University Medical Centre, PO Box 9600, 2300 WB Leiden, The Netherlands \\ ${ }^{\mathrm{b}}$ Department of Oncology, Leiden University Medical Centre, PO Box 9600, 2300 WB Leiden, The Netherlands \\ ${ }^{c}$ Department of Medical Statistics, Leiden University Medical Centre, PO Box 9600, 2300 WB Leiden, The Netherlands
}

\section{Keywords:}

Cancer

Sexual health

Medical oncology

Sexual dysfunction

Quality of life

Nurse's practice patterns

Attitude of health personnel

Questionnaires

\begin{abstract}
A B S T R A C T
Purpose: In most types of cancer, the disease and its treatment can result in altered sexual function (SF). Oncology nurses are strategically placed to address SF since they have frequent patient interaction. Our aim was to establish their knowledge about and attitudes to SF in oncology care and identify their perceived barriers to addressing the subject.

Methods: A 37-item questionnaire was administered during the 2012 Dutch Oncology Nursing Congress and mailed to 241 Dutch oncology nursing departments.

Results: The majority of 477 nurses (87.6\%) agreed that discussing SF is their responsibility. Discussing SF routinely is performed by $33.4 \%$ of these nurses, consultations mainly consisted of mentioning treatment side-effects affecting SF (71.3\%). There were significant differences depending on experience, knowledge, age, academic degree and department policy. Nurses $\leq 44$ years old $(\mathrm{p}<0.001)$, with $<10$ years oncology experience $(p=0.001)$, insufficient knowledge $(p<0.001)$, no academic degree $(p<0.001)$, and in whose department policy was lacking or inadequate $(\mathrm{p}<0.001)$, were less comfortable discussing SF. Barriers included lack of training, presence of a third party and no angle or motive for initiating discussion. Conclusions: Findings suggest oncology nurses consider counselling on sexual issues to be an important responsibility, in line with discussing other side-effects caused by the disease or its treatment. Nevertheless, cancer patients may not routinely be receiving a sexual health evaluation by oncology nurses. Results emphasize the potential benefit of providing knowledge, including practical training and a complete department protocol.
\end{abstract}

(c) 2015 Elsevier Ltd. All rights reserved.

\section{Introduction}

For most types of cancer, regardless of the patient's age or relationship status, the disease and its treatment can lead to a deterioration in sexual health (Baker et al., 2005; Beckjord et al., 2011; Den Oudsten et al., 2012; Galbraith and Crighton, 2008; Hughes, 2008; Lange et al., 2009; Sadovsky et al., 2010; Wright et al., 2002). The World Health Organisation has addressed sexual health as an integral aspect of wellbeing, defined as 'a state of physical, emotional, mental and social well-being in relation to

\footnotetext{
* Corresponding author. Leiden University Medical Centre, Department of Urology, J3P, PO Box 9600, 2300 WB Leiden, The Netherlands. Tel.: +31 71526 5255; fax: + 31715248135

E-mail address: E.M.Krouwel@lumc.nl (E.M. Krouwel).
}

sexuality; it is not merely the absence of disease, dysfunction or infirmity. Sexual health requires a positive and respectful approach to sexuality and sexual relationships, as well as the possibility of having pleasurable and safe sexual experiences, free of coercion, discrimination and violence' (World Health Organization, 2006). Sexual health cannot be defined without considering sexuality, partially defined as 'a central aspect of being human throughout life and encompasses sex, gender identities and roles, sexual orientation, eroticism, pleasure, intimacy and reproduction' (World Health Organization, 2006). Satisfactory sexual function (SF) (i.e. sexual health despite the presence of disease) is considered to make an important contribution to the quality of life of cancer patients (Flynn et al., 2011; Krebs, 2008; Stead et al., 2003). The disease, however, frequently interferes with SF, leading to sexual dysfunction (SD). With rising long-term survival-rates for cancer, quality of life, including sexual health, is becoming increasingly significant. 
For instance, a reasonable SF provides the patient with the ability to participate in intimate relationships and accordingly assimilate the rehabilitation of self-esteem and physical body function.

Causes of a deterioration in SF in cancer patients are often physically and mentally ambiguous. Surgery, chemotherapy, hormonal agents, radiation therapy, intrinsic disease and psychological disease-related or body image factors may all contribute to a decrease in SF. Despite the fact that it is considered important by both patients and health professionals, patients and survivors have indicated that SF is frequently not addressed by oncology health care providers and an unmet need for information exists (Flynn et al., 2012). According to multifarious studies, compromising data on self-reported practice attitudes and observed practice attitudes, discussing SF with patients is not routinely performed by multidisciplinary oncology health care providers (Flynn et al., 2012; Gamel et al., 1995; Hautamaki et al., 2007; Hordern and Street, 2007; Julien et al., 2010; Kotronoulas et al., 2009; Lavin and Hyde, 2006; Nakopoulou et al., 2009; Olsson et al., 2012; Oskay et al., 2014; Stead et al., 2003; White et al., 2011; Zeng et al., 2011).

Oncology nurses are in a strategic position to be able to address $\mathrm{SF}$, since they have frequent contact with patients when they can provide medical and emotional support for issues of concern during illness, treatment and recovery. Consequently, they are able to identify changes and provide information about the effect of the disease and its treatment on SF. The Oncology Nursing Society (USA) stated in 1979 that sexual health is an integral aspect of quality care in outcome standards for cancer nursing practice (Valencius et al., 1980). The first Dutch national guideline on SF was accepted by the Comprehensive Cancer Centre of the Netherlands (IKNL) in 2006, describing the important position of the oncology nurse in diagnosing and intervening in cancer-related SD (Integraal Kankercentrum Nederland, 2006).

Although discussing SF is officially stated as an important component of oncology nursing practice worldwide, many nurses experience barriers in actually discussing psychological or physiological aspects of SF. Barriers identified in previous publications involved factors like incorrect assumptions regarding sexual issues, discomfort, lack of knowledge (Kotronoulas et al., 2009), 'it is not my responsibility', embarrassment (Stead et al., 2003), patients do not expect nurses to discuss sexual concerns, confidence (Julien et al., 2010), lack of training, difficult to bring up the subject and lack of time (Hautamaki et al., 2007). Furthermore, it was shown that cancer patients, who themselves had to initiate discussion with an oncology professional about SF, already experienced significantly greater SD than those who did not bring up the subject (Flynn et al., 2012). The fact that routine nursing practice currently neglects addressing SF is emphasized by patients who state that more attention should be paid to SD (Hill et al., 2011; Hordern and Street, 2007; Stead et al., 2003). While health care professionals do little to address SF (Bekker et al., 2009, 2011; Nicolai et al., 2013; Saunamaki et al., 2010), patients with all types of cancer are willing to talk about their sex lives and the impact of the disease on their SF (Ananth et al., 2003; Hill et al., 2011). For over thirty years, international nursing and treatment guidelines have highlighted the importance of discussing SF and providing additional information. In their daily practice, however, nurses often avoid responding or fail to respond to patients' sexual concerns. Considering the incidence, the influence on quality of life and the patients' need to discuss the impact of disease on SF, there is much room for improvement in sexual health care provision in oncology departments.

Our aim was to investigate nurses' knowledge about and opinions on the responsibility for addressing SF in oncology treatment settings in The Netherlands, as well as looking at their attitudes to the subject and identifying what they consider as barriers to addressing it. In addition, the possible wish of oncology nurses for supplementary education and practical training in counselling on sexual matters was investigated. Several previous studies have recommended future research using a larger sample, in order to have a more representative overview. Since conflicting findings have been reported worldwide and as the studies performed have been mostly qualitative, based on a single centre and relatively small samples, we considered it essential to investigate the Dutch nurses' attitudes and practice behaviour in a nationwide quantitative study design (Kotronoulas et al., 2009). We postulated that most Dutch oncology nurses are aware of the possible impact of cancer diagnosis and treatment on SF, but they do not routinely take a sexual history because of difficulties in bringing the subject up and stereotypical assumptions about sexuality in the face of cancer. This study was performed as part of an extensive study on possible omissions regarding attention paid to SF in oncology care, in order to develop sexual health care solutions for cancer patients in future.

\section{Methods}

\section{Study design}

Data for this cross-sectional survey were collected using a questionnaire. The sample consisted of Dutch nurses involved with oncology patients working in various departments in several clinical settings. Our sampling strategy aimed to be representative with regard to tumour site, employment setting, level of education, years of oncology experience, type of hospital, age and gender.

\section{Instrument design and development}

The established Sexuality Attitudes and Beliefs Survey (SABS) assesses nurses' attitudes to and views on human sexuality with 12 items presented in a Likert-type format (1-6 levels of agreement) (Reynolds and Magnan, 2005). In order to acquire extensive information on all relevant factors covering the aim of this study, not included in the SABS, it was decided to design a more comprehensive questionnaire. The current questionnaire design does, however, comprise items addressed in the SABS. The 37-item questionnaire was developed by the corresponding author (E.M.K.) in cooperation with an expert-panel, consisting of an experienced sexology researcher (M.P.J.N.), a urologist-sexologist (H.W.E.), a professor of oncology (S.O.) and an oncology research nurse (A.Q.M.J.v.S) (Appendix 1). A literature review was conducted to find other surveys in the field of nursing and sexuality, in order to merge all relevant items, barriers and what was not yet known. The design made use of previous surveys among health care providers (Bekker et al., 2011; Nicolai et al., 2013), studies which measured adequately attitudes regarding sexuality. After the initial instrument design, the authors individually scored all items for content validity. Items scored as non-essential by multiple authors were removed. The pilot questionnaire was reviewed by 10 anonymous oncology nurses from the LUMC (Leiden University Medical Centre) and modified using their feedback. In the pilot, the questionnaire was tested for length, layout, linguistic inaccuracies, identification of problematic questions, advice on content, whether response choices were appropriate and whether respondents followed directions. On the basis of the pilot, irrelevant questions were removed and minor linguistic changes and question order modifications made.

The final version comprised a demographic sheet and Likertscale items (ranging from 1 to 5 levels of agreement) measuring practices, attitudes, content of sexual counselling, responsibility, need for education and barriers regarding discussing SF and fertility 
issues. Demographic data included professional background, experience in oncology practice, gender and age. Internal and external barriers, which, on the basis of literature, were assumed to be present, included patients' age, partnership, culture, language, privacy, state of disease, prognosis and other possible restraints. All results were compared, taking into account demographic respondent information which might be relevant, such as age, gender, experience and knowledge. We also investigated the existence of local protocols and perceptions concerning the responsibility for addressing SF, in order to clarify whether or not this is indeed a nursing responsibility. All responses were processed anonymously. Questionnaires were included for analysis when the participant had completed at least the most relevant items. These were the demographic characteristics and the questions on practice patterns regarding how often sexual counselling took place, as this was the main outcome. Data concerning fertility issues were processed separately.

\section{Reliability}

Two questions with 5 Likert scales on the subject, how often do nurses address sexual health with new patients compared to follow-up settings, had a Cronbach's alpha of 0.80 . Scores on reliability of two questions with 5 Likert scales regarding nurses knowledge about SF also demonstrated good internal consistency (Cronbach's $\alpha=0.80$ ). The Cronbach's $\alpha$ scores for the subscales on matching barriers ranged from 0.61 to 0.91 , respectively, with $2-3$ barriers in every corresponding dimension and 5 Likert scales per item. Items corresponded as far as cultural/religious/ethnical and language barriers were concerned, knowledge and complexity, barriers addressing embarrassment and barriers to raising the topic.

\section{Survey administration}

The questionnaire was available as a web-based and a paper version. The web-based version was promoted on several online Dutch oncology nursing platforms, including that of the Dutch Oncology Nursing Society, relevant social media groups and the website, www.nursing.nl. The link was e-mailed to all available addresses of hospitals and oncology nursing departments throughout The Netherlands with the request to distribute this amongst employed oncology nurses. Web-based data were collected from September 2012 to December 2012. The paper version was handed out during the annual Dutch Oncology Nursing Congress held in Ede on 27-28 November 2012 and delegates (with the exception of those nurses who had already participated via the Web) were asked to complete the questionnaire before leaving the congress. Recruiters at the Congress approached nurses in order to obtain informed consent. Nurses who had already participated via the Web did not receive a copy. Each nurse who participated during the Congress received a book on cancer and sexuality. Data from the web-based survey and the congress survey were processed together. The ten responses from the pilot survey were added to the final analysis group, since these nurses completed all answers and only small modifications had been made.

\section{Statistical methods}

Data analysis was performed using SPSS (Release 20.0; SPSS Inc.). The internal consistency of the questionnaire was measured using Cronbach's coefficient $\alpha$. The results were described using frequency distribution. Observed differences between demographic information and specific answers were identified using the Pearson's chi-square test; McNemar's test was applied for paired nominal data. Comparison between demographic information from congress respondents and web-based respondents was performed with the Student's t-test and Pearson's chi-square test. $P$-values $<0.05$ were considered statistically significant.

\section{Ethical considerations}

In The Netherlands, research that does not involve patients or interventions, is not subject to approval from ethical boards. In previous research where nurses were the participants, the Medical Ethics Committee was consulted in order to verify whether ethical approval was necessary. As the study did not concern any information recorded by the investigator in such a manner that subjects could be identified, directly or through identifiers linked to the subjects, and as it did not compromise the study participants' integrity, the Committee declared that no formal ethical approval was needed (Bekker et al., 2011). However, ethical principles were taken into consideration. With regard to the principle of autonomy, participation in the survey was completely voluntary. Information was provided about the study aims and highlighted the anonymous nature of the survey. Each respondent had to state approval before participating and an opt-out possibility was implemented. The principle of justice, beneficence and non-maleficence are not applicable, since the survey does not involve an actual intervention. The anonymous survey does not harm or benefit the nurses in any way.

\section{Results}

\section{Participants}

The sample consisted of Dutch nurses involved with cancer patients working on various departments in several clinical settings, as defined in Fig. 1 and Table 1. A total of 431 nurses completed the survey and were included in this study. A further 46 questionnaires were completed as far as the most relevant items were concerned; these were also included. All other incomplete forms were excluded from analysis; note that these incomplete forms were submitted by the group using the web-based version. 128 nurses (26.8\%) were recruited during the congress, 339 questionnaires $(71.1 \%)$ were collected via the website, 10 nurses $(2.1 \%)$ were included from the LUMC pilot, making a total of 477 eligible respondents. For accurate information about study design, respondents and reasons for refusal, see the study flow chart displayed in Fig. 2.

\section{Participant characteristics}

Demographics from the congress and the online data sets were compared; no significant differences were found concerning age $(p=0.73)$, gender $(p=0.23)$, type of hospital $(p=0.31)$, function $(p=0.27)$ or experience $(p=0.66)$. Small differences were seen regarding areas of expertise (classified by tumour site), as slightly more nurses recruited during the congress had expertise in haematology (46\% versus 33\%; $\mathrm{p}=0.01$ ), nephrology and urology $(41 \%$ versus $31 \% ; \mathrm{p}=0.03$ ), gynaecology ( $47 \%$ versus $37 \% ; \mathrm{p}=0.04$ ) and head and neck oncology ( $28 \%$ versus $19 \% ; \mathrm{p}=0.04$ ). There was no significant difference in distribution of other areas of expertise among the respondents ( $p$ ranged from 0.07 to 0.41 ).

All participants were oncology nurses, a considerable number of whom had a degree (22.9\%). The majority of the nurses were female (90.8\%), their ages ranging from 19 to 62 years (median $=44$ years). The demographic details are outlined in Table 1. See Fig. 1 for the distribution over areas of expertise in oncology. 


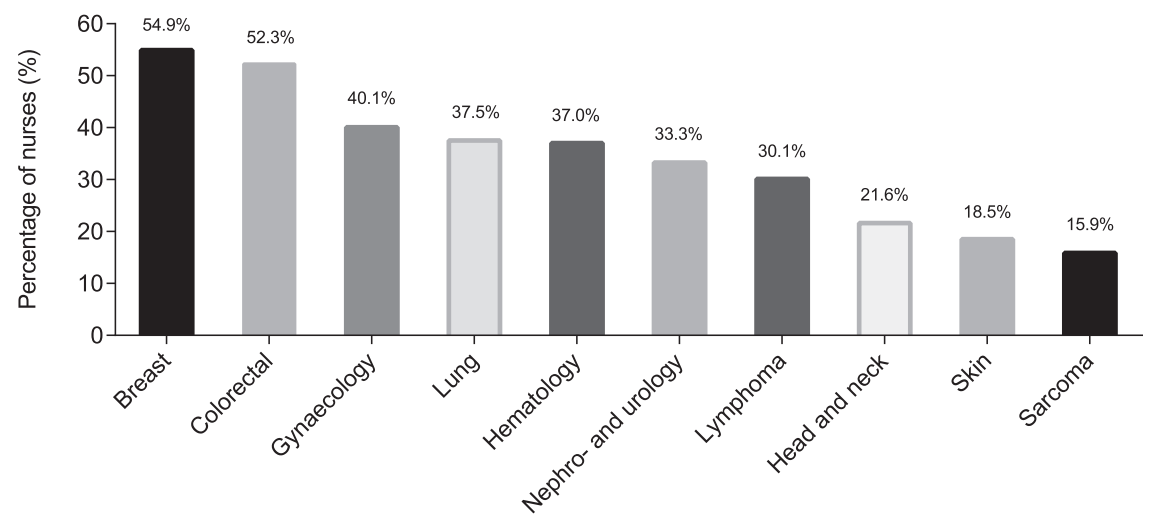

a) Please note that some nurses were employed at multiple departments and some nurses did not specify an area of
expertise.

Fig. 1. Distribution of nurses in relation to the areas of expertise, classified by tumour site $(n=459){ }^{a}$

\section{Practice patterns}

Participants believed that, in general, 69.7\% (SE 1.4) of cancer patients experience some kind of altered SF due to disease and/or treatment $(n=265)$. The oncology nurses were asked whether or not they routinely asked about SF and how often they thought the

Table 1

Demographic characteristics of participating nurses.

\begin{tabular}{|c|c|}
\hline Demographic characteristics $(n=477)$ & $\mathrm{n}(\%)$ \\
\hline Age (years) & $460(96.4)$ \\
\hline \multicolumn{2}{|l|}{ Median 44 years (range $19-62$ ) } \\
\hline \multicolumn{2}{|l|}{ Mean 42.2 years } \\
\hline \multicolumn{2}{|l|}{ Gender } \\
\hline Male & $30(6.3)$ \\
\hline Female & $433(90.8)$ \\
\hline Unknown & $14(2.9)$ \\
\hline \multicolumn{2}{|l|}{ Oncology experience (years) } \\
\hline$<1<-<1<$ & $13(2.7)$ \\
\hline $1-2$ & $32(6.7)$ \\
\hline $3-5$ & $89(18.7)$ \\
\hline $6-10$ & $87(18.2)$ \\
\hline $11-15$ & $92(19.4)$ \\
\hline$>15$ & $150(31.4)$ \\
\hline Unknown & $14(2.9)$ \\
\hline \multicolumn{2}{|l|}{ Employment setting } \\
\hline Registered nurse $^{a}$ & $84(17.6)$ \\
\hline Registered nurse currently in Oncology registration training & $22(4.6)$ \\
\hline Registered nurse with Oncology certificate ${ }^{\mathrm{b}}$ & $215(45.1)$ \\
\hline \multicolumn{2}{|l|}{ Clinical setting } \\
\hline - Inpatient & $92(19.3)$ \\
\hline - Outpatient & $105(22)$ \\
\hline - In/out-patient & $18(3.8)$ \\
\hline Registered nurse with graduate degree ${ }^{c}$ & $109(22.9)$ \\
\hline Nurse in charge of Oncology department ${ }^{\mathrm{d}}$ & $10(2.1)$ \\
\hline Research nurse & $7(1.5)$ \\
\hline District nurse with Oncology specialism ${ }^{\mathrm{e}}$ & $8(1.6)$ \\
\hline Different/unknown & $22(4.6)$ \\
\hline \multicolumn{2}{|l|}{ Hospital type } \\
\hline University hospital & $163(34.2)$ \\
\hline District general teaching hospital & $141(29.6)$ \\
\hline District general hospital & $149(31.2)$ \\
\hline Extramural & $8(1.6)$ \\
\hline Unknown & $16(3.4)$ \\
\hline
\end{tabular}

a Involved vocational trained nurses as well as bachelor's degree nurses with no registered specialism but currently employed in an oncology department.

${ }^{b}$ Involved nurses with official Oncology registration (acknowledged by the Dutch board of Hospital Education) following 1 year official Oncology training.

c Involved nurses with a graduate degree from a University of Professional Education or a University of Science, usually involved with in- and outpatient departments.

d Clinical setting undefined.

e Involved nurses caring for cancer patients at home. oncologists discussed SF; several other practice patterns were also explored. Regarding the question 'How often do you discuss SF?' nurses indicated the following statistics: never/rarely: $18.9 \%$; in less than half of the cases: $32.6 \%$; in half of the cases: $15.1 \%$; in more than half of the cases: $13.4 \%$; and often/always: $20 \%$. Oncology nurses $>44$ years discussed SF significantly more often than nurses $\leq 44$ years (Pearson Chi-Square, $\mathrm{p}=0.009$ ). Graduate oncology nurses discussed SF significantly more frequently compared to the other nurses (Pearson Chi-Square, $\mathrm{p}<0.001$ ). Moreover, experienced nurses ( $>10$ years in oncology practice) discussed SF significantly more often than less experienced nurses (Pearson ChiSquare, $\mathrm{p}=0.001$ ). An equally strong correlation was found between level of knowledge and discussing SF (Fig. 3). Nurses with the self-scored knowledge levels 'not any', 'not so much' and 'some', discussed SF less often than nurses with 'sufficient' and 'a lot' of knowledge (Pearson Chi-Square, $\mathrm{p}<0.001$ ). Seventy-four percent of the nurses estimated that the oncologist never, rarely or in less than half of the cases discussed SF with the patients. Further data about practice attitudes regarding SF are featured in Table 2.

Depending on the type of treatment, significant differences were observed in percentage of nurses discussing SF: treatment with intent to cure, $83.2 \%(\mathrm{n}=396)$; life-prolonging treatment, $57.1 \%(n=272)$; and palliative treatment $44.5 \%(n=212)(\mathrm{McNe}-$ mar's test $\mathrm{p}<0.001$ ). With regard to age, results show that oncology nurses never/rarely discuss SF with patients aged 66-75 years $(60.8 \%, n=472)$ or those over 76 years $(73.1 \%, n=465)$. For younger patients, a majority of the oncology nurses said they discussed SF regularly/often: in $60 \%$ of patients aged 16-35 years $(n=467), 63.1 \%$ of those aged $36-50$ years $(n=470)$ and $57.2 \%$ of the 51-65-year age group $(n=473)$.

\section{Responsibility}

The majority of oncology nurses (87.6\%) agreed that the oncology nurse is responsible for discussing SF as far as diseaserelated and treatment-related problems were concerned. An almost equal majority (88.7\%) stated that the oncologist also bears responsibility for discussing SF. On the other hand, $42 \%$ of the nurses considered it to be the patient's responsibility to raise their sexual concerns during a consultation $(n=469)$.

\section{Availability of local policy or agreement}

$55.4 \%$ of the respondents noted that a local policy or agreement was in place for discussing SF as standard routine. Approximately a 


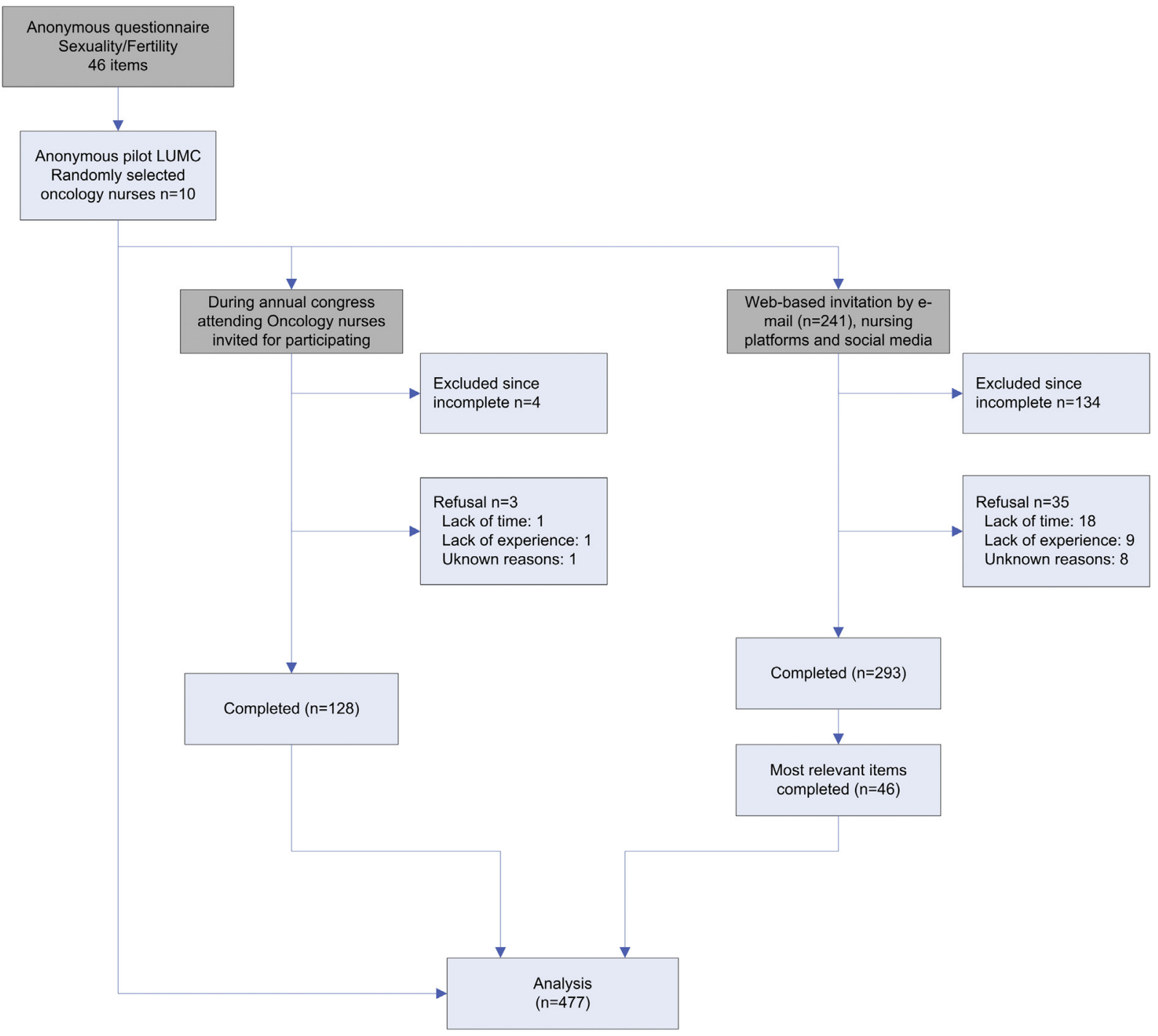

Fig. 2. Study flow diagram showing study design and respondents/non-respondents.

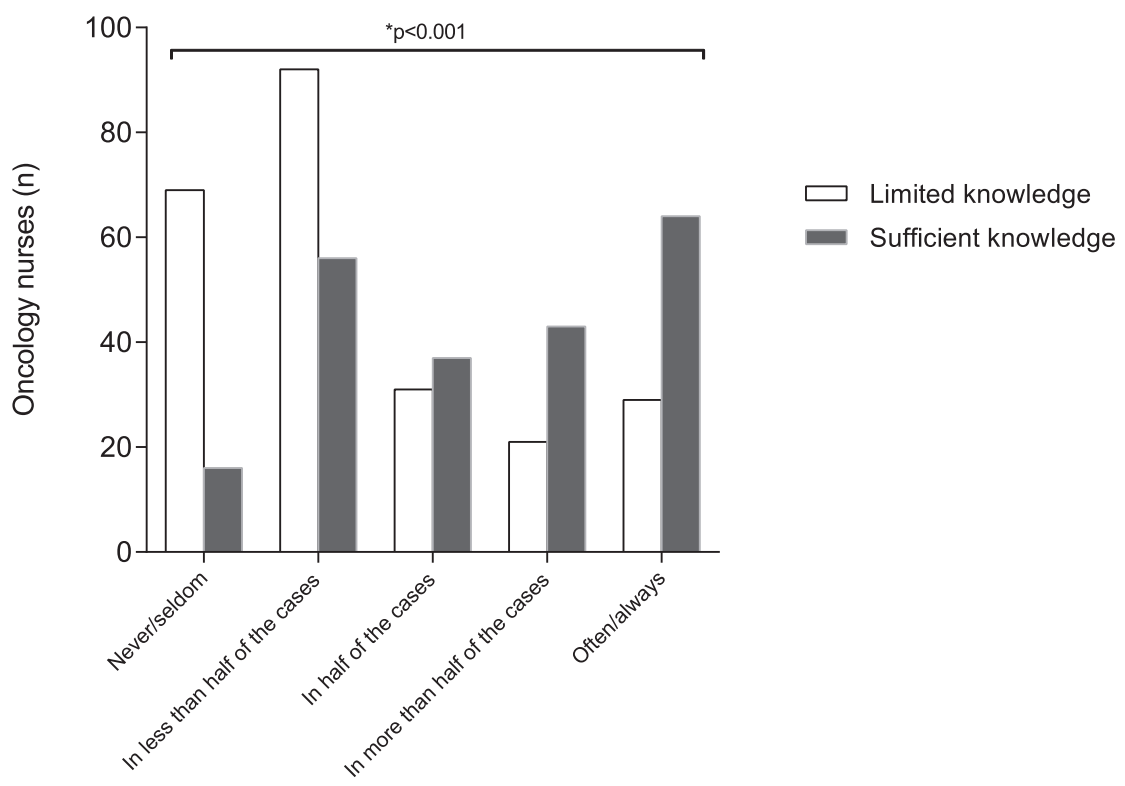

Fig. 3. Level of knowledge about sexual dysfunction following cancer in relation to the frequency of discussing sexual function ( $\mathrm{p}<0.001 \mathrm{Pearson}$ Chi-Square, $\mathrm{n}=458$ ). 
Table 2

Frequency distributions on questions in relation to discussing sexual function.

\begin{tabular}{|c|c|c|c|c|c|}
\hline \multirow[t]{2}{*}{ Items: How often... } & \multirow{2}{*}{$\begin{array}{l}\text { Never/Rarely } \\
\overline{n(\%)}\end{array}$} & \multirow{2}{*}{$\begin{array}{l}\text { Less than half } \\
\text { of the cases } \\
n(\%)\end{array}$} & \multirow{2}{*}{$\begin{array}{l}\text { Half of } \\
\text { the cases } \\
\frac{n(\%)}{}\end{array}$} & \multirow{2}{*}{$\begin{array}{l}\text { More than half } \\
\text { of the cases } \\
n(\%)\end{array}$} & \multirow{2}{*}{$\begin{array}{l}\text { Often/Always } \\
n(\%)\end{array}$} \\
\hline & & & & & \\
\hline Do you discuss sexual function of the patient & $90(18.9)$ & $155(32.6)$ & $72(15.1)$ & $64(13.4)$ & $95(20)$ \\
\hline Do you think that sexual function is discussed with the oncologist & $144(30.2)$ & $211(44.2)$ & $73(15.3)$ & $37(7.8)$ & $12(2.5)$ \\
\hline Patients present sexual function complaints spontaneously & $261(56.4)$ & $170(36.7)$ & $19(4.1)$ & $8(1.7)$ & $5(1.1)$ \\
\hline Do you make sure that sexual function is discussed with a new patient & $109(23.7)$ & $110(23.9)$ & $56(12.2)$ & $77(16.7)$ & $108(23.5)$ \\
\hline Do you discuss sexual function during check-up appointments & $187(43.1)$ & $120(27.6)$ & $48(11.1)$ & $38(8.8)$ & $41(9.4)$ \\
\hline Is the partner of the patient present during sexual function conversation & $55(12.6)$ & $101(23.1)$ & $75(17.2)$ & $107(24.5)$ & $98(22.5)$ \\
\hline Do you ask about the sexual orientation of the patient & $297(68.1)$ & $55(12.6)$ & $16(3.7)$ & $25(5.7)$ & $43(9.9)$ \\
\hline Do you discuss contagiousness of cancer with the patient & $250(59.5)$ & $65(15.5)$ & $22(5.2)$ & $33(7.9)$ & $50(11.9)$ \\
\hline Do you discuss transmitting chemo agents during intercourse & $110(26.1)$ & $51(12.1)$ & $39(9.2)$ & $58(13.7)$ & $164(38.9)$ \\
\hline
\end{tabular}

third of the nurses (29\%) stated there was no such agreement or policy in place and $15.6 \%$ reported that they did not know if their department had such a policy. According to $31.3 \%$ of the nurses, it was policy to inform patients about treatment-related sexuality issues. Only $24.1 \%$ of the nurses reported that the department policy stated that sexuality should be discussed throughout treatment $(n=469)$. Nurses in such a department discussed SF with their patients significantly more frequently (Pearson Chi-Square, $\mathrm{p}<0.001)$. The majority of respondents $(85.8 \%)$ stated that SF is not discussed in a multidisciplinary consultation $(n=416)$.

\section{Knowledge and training}

Regarding knowledge levels, a majority stated they had 'some knowledge' or 'sufficient knowledge' about SD related to oncological illness (41.7\% vs. 38.2\%). An almost equal number of nurses stated they had 'some knowledge' or 'sufficient knowledge' about treatment-related SD (38.9\% vs. $42.5 \%$ ). However, in response to the questions concerning solutions for $\mathrm{SD}, 47.9 \%$ reported having 'some knowledge', 24.8\% reported having 'not so much knowledge' $(\mathrm{n}=459)$. In answer to the question 'Would you like to acquire more knowledge on how to address sexual issues?' $76.3 \%$ replied positively ( $n=422) .63 \%$ of the nurses stated that current oncology training does not sufficiently cover the assessment of SF $(n=400)$.

\section{Techniques for discussing SF}

With a view to broaching the subject of SF, $71.3 \%$ of the nurses stated they only addressed the issue of possible sexual side-effects and $43.3 \%$ stated they only informed the patient rather than questioning him/her. A further $40.5 \%$ stated they only discussed SF if the patient mentioned the subject $(n=443)$. A small group reported using humour (20.5\%). More than half of the nurses ( $\mathrm{n}=438$ ) enquired about fatigue (65.1\% in female, $59.8 \%$ in male) and insecurity due to altered self-image (56.4\% in female, $42.3 \%$ in male). Less than a third of the nurses asked their female patients if vaginal dryness was a problem (28.5\%), but $51.7 \%$ of the nurses asked male patients about erectile dysfunction. We also asked about the availability of written information for patients. Over half of the nurses stated that such information is not available in their department $(56 \%, \mathrm{n}=441)$.

\section{Barriers}

The oncology nurses were given a list of possible barriers to discussing SF, in order for them to indicate the extent to which they agreed (Table 3). Nurses mentioned 'lack of training' as a major barrier (42\%). The second barrier, with which $41.2 \%$ of the nurses agreed, was 'presence of a third party'. Other barriers, with agreement by about a third of the respondents, were 'no angle or motive for asking' (32\%), 'advanced age of the patient' $(30.8 \%)$ and 'language/ethnicity' (30.3\%). The least consensus was reached on the barriers: 'colleagues think it is inappropriate if I discuss SF with patients' (1.1\%) and 'patient is the same gender' (1.4\%).

\section{Importance}

The importance of assessing SF in oncology patients was addressed at the end of the questionnaire $(n=414)$. A majority of the nurses (56\%) considered the need to assess SF as 'important'; an additional number stated it was 'very important' (13.8\%). The remaining respondents indicated it was 'important to some extent' (27.1\%), 'not very important' $(2.4 \%)$ or 'unimportant' $(0.7 \%)$. According to the responding oncology nurses, patients with whom SF should be discussed hardly bears any relation to the tumour site (Table 4). Most nurses thought SF should definitely be discussed with breast cancer patients (95.7\%) and gynaecological cancer patients (94.0\%). By contrast, according to $2.6 \%$ of the nurses, it was not necessary to discuss SF. For a complete summary of the patients with whom sexuality should be discussed per type of cancer, see Table 4.

\section{Discussion}

\section{Key findings}

This survey provides extensive data on routine practice regarding sexual health issues in a nationwide sample of Dutch oncology nurses. It also looks at the level of knowledge about these issues and the barriers to tackling them. Participating nurses estimated that the majority of cancer patients experience some degree of SD. Generally, a third of the oncology nurses enquire routinely about SF, depending on the patient's age and type of treatment (curative vs. life-prolonging vs. palliative treatment). When questioned further, the nurses who did discuss SF stated they only addressed possible sexual side-effects or informed the patient rather than discussing the sexual concerns. Despite these practice patterns, a majority believed it was their responsibility, as well as that of the oncologist, to provide SF counselling. The strongest barriers to discussing SF found in this study were lack of training, presence of a third party, no angle or motive for asking, advanced age of the patient and different language/ethnicity.

\section{Comparison with other population data}

The findings support and extend previous research in western countries concerning reasons why oncology nurses do not routinely discuss matters of sexuality with cancer patients. Besides routine 
Table 3

Frequency analysis on barriers in relationship to discussing sexual function.

\begin{tabular}{|c|c|c|c|c|c|}
\hline \multirow[t]{2}{*}{ Items: Barriers in discussing sexual function ${ }^{a}$} & \multirow{2}{*}{$\frac{\text { Totally agree }}{n(\%)}$} & \multirow{2}{*}{$\frac{\text { Agree }}{n(\%)}$} & \multirow{2}{*}{$\frac{\text { Partly agree/partly disagree }}{n(\%)}$} & \multirow{2}{*}{$\frac{\text { Disagree }}{n(\%)}$} & \multirow{2}{*}{$\frac{\text { Totally disagree }}{n(\%)}$} \\
\hline & & & & & \\
\hline Lack of training & $32(7.5)$ & $148(34.5)$ & $123(28.7)$ & $93(21.7)$ & $33(7.7)$ \\
\hline Presence of a third party & $22(5.2)$ & $153(36)$ & $121(28.5)$ & $103(24.2)$ & $26(6.1)$ \\
\hline No angle or motive for asking & $15(3.5)$ & $121(28.5)$ & $126(29.7)$ & $109(25.7)$ & $53(12.5)$ \\
\hline Advanced age of the patient & $15(3.5)$ & $117(27.3)$ & 127 (29.6) & $124(28.9)$ & $46(10.7)$ \\
\hline Language/ethnicity & $13(3)$ & $117(27.3)$ & $156(36.4)$ & $118(27.5)$ & $25(5.8)$ \\
\hline Culture/religion & $8(1.9)$ & $117(27.3)$ & $159(37.1)$ & $116(27)$ & $29(6.8)$ \\
\hline Patient is too ill & $17(4.0)$ & $105(24.4)$ & $134(31.2)$ & $130(30.2)$ & $44(10.2)$ \\
\hline Lack of knowledge & $20(4.7)$ & $87(20.3)$ & $136(31.7)$ & $141(32.9)$ & $45(10.5)$ \\
\hline Patient doesn't bring up the subject & $9(2.1)$ & $90(21.1)$ & $104(24.4)$ & $156(36.6)$ & $67(15.7)$ \\
\hline High complexity of sexual disorder & $6(1.4)$ & $89(21)$ & 139 (32.9) & $144(34)$ & $45(10.6)$ \\
\hline I feel uncomfortable & $12(2.8)$ & $71(16.7)$ & $108(25.4)$ & $162(38.1)$ & $72(16.9)$ \\
\hline Patient is not ready to discuss sexual function & $10(2.3)$ & $72(16.7)$ & $142(33)$ & $145(33.7)$ & $61(14.2)$ \\
\hline Lack of time & $17(4)$ & $58(13.5)$ & $81(18.9)$ & $156(36.4)$ & $117(27.3)$ \\
\hline Sexuality is a private matter & $4(0.9)$ & $67(15.7)$ & $134(31.5)$ & $160(37.6)$ & $61(14.3)$ \\
\hline Embarrassment & $1(0.2)$ & $65(15.3)$ & $99(23.3)$ & $188(44.2)$ & $72(16.9)$ \\
\hline Concerned about making patient uncomfortable & $0(0)$ & $52(12.1)$ & $113(26.3)$ & $192(44.5)$ & $73(17)$ \\
\hline Sexuality is not a patient's concern & $3(0.7)$ & $48(11.2)$ & $128(29.8)$ & $173(40.2)$ & $78(18.1)$ \\
\hline Age difference between you and patient & $5(1.2)$ & $45(10.5)$ & $62(14.5)$ & $226(52.7)$ & $91(21.2)$ \\
\hline Surviving is more important & $4(0.9)$ & $45(10.6)$ & $130(30.6)$ & $168(39.5)$ & $78(18.4)$ \\
\hline Not relevant for all type of cancers & $3(0.7)$ & $35(8.3)$ & $69(16.3)$ & $213(50.2)$ & $104(24.5)$ \\
\hline Afraid to offend the patient & $1(0.2)$ & $37(8.7)$ & $99(23.3)$ & $212(49.9)$ & $76(17.9)$ \\
\hline Sexuality is not a matter of life and death & $1(0.2)$ & $19(4.5)$ & $89(20.9)$ & $229(53.9)$ & $87(20.5)$ \\
\hline It's someone else's task & $1(0.2)$ & $14(3.3)$ & $52(12.1)$ & $190(44.3)$ & $172(40.1)$ \\
\hline No confidence in treatment for sexual dysfunction & $0(0)$ & $14(3.3)$ & $86(20.2)$ & $230(54.1)$ & $95(22.4)$ \\
\hline Patient is the opposite gender & $0(0)$ & $13(3.1)$ & $40(9.4)$ & $230(54)$ & $143(33.6)$ \\
\hline Patient is the same gender & $2(0.5)$ & $4(0.9)$ & $22(5.1)$ & $259(60.4)$ & $142(33.1)$ \\
\hline Colleagues think it's inappropriate if I discuss sexual function with patients & $1(0.2)$ & $4(0.9)$ & $31(7.3)$ & $222(52.0)$ & 169 (39.6) \\
\hline
\end{tabular}

${ }^{a}$ Barriers sorted descending from most agreed (totally agree + agree) to least agreed (disagree + totally disagree).

practice, this study describes various issues involved in the process of sexual counselling, which help to interpret the data. Previous studies had less-representative samples; they were small, based on a single-centre, unequal in age distribution, or included other health care workers in the sample (Kotronoulas et al., 2009). The present study describes a high rate of acceptance that SF consultation should be both the nurses' (87.6\%) and the physicians' (88.7\%) responsibility compared to earlier studies, in which nurses stated that addressing SF was not included in their task, with $62.5 \%-78 \%$ regarding it as being their responsibility (Hautamaki et al., 2007; Nakopoulou et al., 2009; Saunamaki et al., 2010). This finding might be the result of a growing awareness of the sexual burden in cancer patients within the last 20 years. However, the

Table 4

Patients with who sexual function should be discussed according to respondents ( $n$ $=416)$.

\begin{tabular}{lr}
\hline Type of patients & $\begin{array}{l}\text { Nurses agreeing sexual } \\
\text { function should be discussed } \\
\text { with these patients }\end{array}$ \\
\cline { 2 - 2 } & \multicolumn{1}{c}{$n(\%)$} \\
\hline Breast cancer & $398(95.7)$ \\
Gynaecological cancer & $391(94.0)$ \\
Urological cancer & $368(88.5)$ \\
Colorectal cancer & $366(88.0)$ \\
Haematological cancer & $295(70.9)$ \\
Head/neck cancer & $293(70.4)$ \\
Lung cancer & $280(67.3)$ \\
Nephrological cancer & $277(66.6)$ \\
Lymphoma & $270(64.9)$ \\
Palliative cancer care & $262(63.0)$ \\
Neuro-endocrine cancer & $257(61.8)$ \\
Sarcoma & $255(61.4)$ \\
Skin cancer & $254(61.1)$ \\
I do not believe it is necessary & $11(2.6)$ \\
$\quad$ to discuss sexual function & \\
\hline
\end{tabular}

level of knowledge concerning SF remains unsatisfactory. We found a similar frequency of discussing SF as a recent study from Finland, in which a third of the oncology nurses stated they discussed SF fairly frequently, also influenced by work experience. Their cut-off point was, however, 2 years whereas ours was 10 years (Hautamaki et al., 2007). Factors influencing the provision of sexual counselling correspond to a previous study from The Netherlands, indicating that little has changed. Age, experience and knowledge also correlated positively with routinely addressing SF (Gamel et al., 1995). Julien et al. described that nurses aged younger than 40 years reported more barriers than older nurses. This is similar to our finding regarding nurses' age influencing incidence of discussing SF. In contrast to our data, in this sample, the level of education was not correlated with the barriers experienced in relation to sexual counselling (Julien et al., 2010). The main barrier, 'lack of training', matched other studies, where lack of training and lack of knowledge were given as the main reasons for not assessing SF. This supports our finding that adequate training is one of the main determining factors (Bekker et al., 2011; Gamel et al., 1995; Hautamaki et al., 2007; Nicolai et al., 2013). Contrary to findings in a Chinese oncology nursing study, time and 'sexuality is a private matter' are hardly mentioned as barriers in western studies (Zeng et al., 2011). It is helpful to realize that time is not a barrier for discussing SF, despite the current cost reductions which may result in an increased burden for health care providers.

\section{Sexual counselling}

The present study reveals an apparent incongruity between treatment objectives and their implementation. Despite the fact it was relatively rare for nurses to take the initiative in discussing sexuality-related issues, the majority acknowledged that it is part of their job and also the responsibility of the oncologist. Not every patient needs extensive discussion about sexual issues. We do, however, believe that as a part of informed consent for several 
treatments or as a result of disease, the issue should be addressed at some point. Furthermore, if the subject is simply addressed once, the patient can then decide themselves to bring it up again. The challenge is for the nurse to raise the subject, and if the patient expresses interest in discussing it, to do so. The strong association between the frequency of discussing SF and nursing experience, specialization and self-reported knowledge, supports the evident need for expanding educational activities. This is reinforced by a majority of the nurses stating they would like to acquire more knowledge, specifically about possible solutions for cancer-related SD. This survey did not take into account whether nurses had received any education on handling sexual issues in the past, an aspect which could be interesting in future survey research. During training, we recommend that the importance of discussing SF with cancer patients be highlighted, not only with the obviously affected patient (i.e. breast-, gynaecological-, urological- and colorectal patients). SF is also affected in other cancers, as it can deteriorate due to many causes including relationship issues, fatigue and changed appearance as a result of surgery or chemotherapy. Most nurses in this survey seemed aware that SF is of great importance in all forms of cancer; fewer believed that SF should be discussed with cancers not involving the breast, intestines or genitals. Lemieux et al. showed the importance of addressing SF even in a palliative treatment setting which unfortunately, according to our study, hardly ever happens, with a special role for the district nurse (Lemieux et al., 2004). Furthermore, a very important component is the presence of a local policy or agreement regarding initiating discussions on SF as a matter of routine. This study exposed the clear relationship between the availability of such a policy and the actual frequency of mentioning SF in a consultation. The considerable lack of availability and lack of awareness of local agreement on sexual counselling as a matter of routine should be a significant point of interest for heads of nursing departments.

Clearly, not every nurse should be forced into the role of sexual counsellor, since not everyone is able to discuss this controversial subject, for example because of private circumstances such as a bad sexual experience or religion. For this reason, considerable benefit could be derived by implementing a clinical nurse specialist on quality of life and sexuality, as investigated for gynaecological oncology purposes with successful results (Maughan and Clarke, 2001). Further research should investigate (1) the role other oncology health care providers could play in sexual counselling, (2) who could act as the coordinating staff member and (3) how to implement solutions beneficial to the unmet need for information.

\section{Study limitations and strengths}

Possible limitations of this study demand some reflection. The results presented are of self-reported attitudes and those nurses who responded are more likely to be those already familiar with addressing sexual health issues. Efforts were made to ensure a more neutral response group by securing the anonymous nature of the survey, convincing nurses of the importance of this survey and providing a reward in the form of books in exchange for participation as an incentive to motivate less-concerned nurses.

The administered questionnaire was non-validated, since validated instruments like the SABS did not incorporate the main objectives and additional study aims (Reynolds and Magnan, 2005). In epidemiology, it is a well-known fact that re-using standard questionnaires will not necessarily point towards the exposure of interest, especially not when translated from another language (Silman and MacFarlane, 2002). However, all topics of the SABS were included and attempts were made to test for validity and reliability. The internal consistencies of the most important items of the questionnaire tested as acceptable to excellent. Test-retest reproducibility of the questionnaire was not tested; this was impossible due to the anonymous pilot design and study design.

Cultural, religious and partnership status of respondents were excluded in response to the pilot panel's decision; they felt they might have made the questionnaire too sensitive. Demographic particulars of the nurses indicated a heterogeneous sample regarding age and experience, although not for gender, since the majority were female. Comparison between the congress respondents and web-based respondents resulted in minor demographic differences regarding area of expertise; all other demographics were comparable. The Dutch Oncology Nursing Society currently has approximately 2400 members; hence the sample of 477 respondents in our survey is deemed sufficiently representative of the Dutch oncology nursing population (Bartlett et al., 2001). This is reinforced by the fact that the congress sample and the web-based sample were almost similar, suggesting our sample is a credible reflection of the total oncology nursing population. Finally, it was not possible to calculate the actual response rate, due to the combination of manual provision of questionnaires and the anonymous web-based design. The web-based survey revealed a high number of incomplete forms. Explanations for the high incompletion rate are technical website issues and the anonymous web-based form which could not be continued at a later stage if time was short. Nor was it possible to estimate the extent of a non-response or a sampling bias. However, the interpretation of the response rate in general is questionable, since even a high response rate does not obviate a non-response bias (Barclay et al., 2002).

\section{Conclusion}

Overall, the present study revealed that oncology nurses consider counselling on sexual issues to be an important responsibility, in line with discussing other side-effects caused by the disease or its treatment. Nevertheless, findings suggest that cancer patients may not routinely be receiving a sexual health evaluation by oncology nurses. While taking sexual histories on a routine basis is believed to enhance the quality of life, oncology nurses believed that oncologists address the subject rarely. The strongest barriers to discussing SF were lack of training, presence of a third party, no angle or motive for asking, advanced age of the patient and different language/ethnicity. Sexual counselling is provided significantly more often by nurses who have undergone further training, are more experienced, older, possess an academic degree and work in a department with a strict policy concerning SF. This emphasizes the potential effect of providing adequate knowledge and appropriate practice training. Policies and patient information regarding SF should be available in all nursing care units.

\section{Implications for oncology nursing practice}

We sincerely hope that this study has emphasized the importance of discussing SD with all cancer patients and that the evidence presented will encourage nurses to address this often overlooked issue, thereby moving a step closer towards improving the quality of life of cancer patients. Oncological health care providers should agree on when and to which extent SF should be discussed, and in particular by whom.

\section{Conflicts of interest}

There are no conflicts of interest to disclose. 


\section{Funding Source}

This study was initiated by the Pelvic Floor and Sexuality Research Group Leiden. The study was supported by the Target Fund Urology of the Leiden University Medical Centre Bontius Foundation and an unrestricted grant from AstraZeneca.

\section{Acknowledgements}

First of all, we are very grateful to the many nurses who voluntarily participated in our survey. We would also like to thank Caroline de Jong-Mom and Liza Lima Setyawan for their assistance in collecting and importing the data. Linguistic supervision was performed by Mrs. Brenda Vollers-King.

\section{Appendix A. Supplementary data}

Supplementary data related to this article can be found at http:// dx.doi.org/10.1016/j.ejon.2015.05.005.

\section{References}

Ananth, H., Jones, L., King, M., Tookman, A., 2003. The impact of cancer on sexual function: a controlled study. Palliative Medicine 2, 202-205.

Baker, F., Denniston, M., Smith, T., West, M.M., 2005. Adult cancer survivors: how are they faring? Cancer 11 (Suppl. 1), 2565-2576. http://dx.doi.org/10.1002/ cncr.21488.

Barclay, S., Todd, C., Finlay, I., Grande, G., Wyatt, P., 2002. Not another questionnaire Maximizing the response rate, predicting non-response and assessing nonresponse bias in postal questionnaire studies of GPs. Family Practice 1, 105-111.

Bartlett, J.E., Kotrlik, J.W., Higgins, C.C., 2001. Organizational research: determining appropriate sample size in survey research. Information Technology, Learning and Performance Journal 19, 43-50.

Beckjord, E.B., Arora, N.K., Bellizzi, K., Hamilton, A.S., Rowland, J.H., 2011. Sexua well-being among survivors of non-Hodgkin lymphoma. Oncology Nursing Forum 5, E351-E359. http://dx.doi.org/10.1188/11.ONF.E351-E359.

Bekker, M., Beck, J., Putter, H., van, D.M., Pelger, R., Lycklama, A.N., et al., 2009. The place of female sexual dysfunction in the urological practice: results of a Dutch survey. Journal of Sexual Medicine 11, 2979-2987. http://dx.doi.org/10.1111/ j.1743-6109.2009.01460.x.

Bekker, M.D., Van Driel, M.F., Pelger, R.C., Nijeholt, G.A., Elzevier, H.W., 2011. How do continence nurses address sexual function and a history of sexual abuse in daily practice? Results of a pilot study. Journal of Sexual Medicine 2, 367-375. http:// dx.doi.org/10.1111/j.1743-6109.2010.02044.x.

Den Oudsten, B.L., Traa, M.J., Thong, M.S., Martijn, H., De Hingh, I.H., Bosscha, K. et al., 2012. Higher prevalence of sexual dysfunction in colon and rectal cancer survivors compared with the normative population: a population-based study. European Journal of Cancer 17, 3161-3170. http://dx.doi.org/10.1016 | j.ejca.2012.04.004

Flynn, K.E., Jeffery, D.D., Keefe, F.J., Porter, L.S., Shelby, R.A., Fawzy, M.R., et al., 2011. Sexual functioning along the cancer continuum: focus group results from the Patient-Reported Outcomes Measurement Information System (PROMIS(R)). Psychooncology 4, 378-386. http://dx.doi.org/10.1002/pon.1738.

Flynn, K.E., Reese, J.B., Jeffery, D.D., Abernethy, A.P., Lin, L., Shelby, R.A., et al., 2012. Patient experiences with communication about sex during and after treatment for cancer. Psychooncology 6, 594-601. http://dx.doi.org/10.1002/pon.1947.

Galbraith, M.E., Crighton, F., 2008. Alterations of sexual function in men with cancer. Seminars in Oncology Nursing 2, 102-114. http://dx.doi.org/10.1016/ j.soncn.2008.02.010.

Gamel, C., Hengeveld, M.W., Davis, B., van der Tweel, I., 1995. Factors that influence the provision of sexual health care by Dutch cancer nurses. International Journal of Nursing Studies 3, 301-314.

Hautamaki, K., Miettinen, M., Kellokumpu-Lehtinen, P.L., Aalto, P., Lehto, J., 2007. Opening communication with cancer patients about sexuality-related issues. Cancer Nursing 5, 399-404. http://dx.doi.org/10.1097/ 01.NCC.0000290808.84076.97.

Hill, E.K., Sandbo, S., Abramsohn, E., Makelarski, J., Wroblewski, K., Wenrich, E.R. et al., 2011. Assessing gynecologic and breast cancer survivors' sexual health care needs. Cancer 12, 2643-2651. http://dx.doi.org/10.1002/cncr.25832.
Hordern, A., Street, A., 2007. Issues of intimacy and sexuality in the face of cancer: the patient perspective. Cancer Nursing 6, E11-E18. http://dx.doi.org/10.1097/ 01.NCC.0000300162.13639.f5.

Hughes, M.K., 2008. Alterations of sexual function in women with cancer. Seminars in Oncology Nursing 2, 91-101. http://dx.doi.org/10.1016/j.soncn.2008.02.003.

Integraal Kankercentrum Nederland, 2006. Richtlijn Veranderd seksueel functioneren, Versie 1.1. IKNL (NL), Comprehensive Cancer Centre the Netherlands, Utrecht.

Julien, J.O., Thom, B., Kline, N.E., 2010. Identification of barriers to sexual health assessment in oncology nursing practice. Oncology Nursing Forum 3 , E186-E190. http://dx.doi.org/10.1188/10.ONF.E186-E190.

Kotronoulas, G., Papadopoulou, C., Patiraki, E., 2009. Nurses' knowledge, attitudes, and practices regarding provision of sexual health care in patients with cancer: critical review of the evidence. Supportive Care in Cancer 5, 479-501. http:// dx.doi.org/10.1007/s00520-008-0563-5.

Krebs, L.U., 2008. Sexual assessment in cancer care: concepts, methods, and strategies for success. Seminars in Oncology Nursing 2, 80-90. http://dx.doi.org/ 10.1016/j.soncn.2008.02.002.

Lange, M.M., Marijnen, C.A., Maas, C.P., Putter, H., Rutten, H.J., Stiggelbout, A.M., et al., 2009. Risk factors for sexual dysfunction after rectal cancer treatment. European Journal of Cancer 9, 1578-1588. http://dx.doi.org/10.1016/ j.ejca.2008.12.014.

Lavin, M., Hyde, A., 2006. Sexuality as an aspect of nursing care for women receiving chemotherapy for breast cancer in an Irish context. European Journal of Oncology Nursing 1, 10-18. http://dx.doi.org/10.1016/j.ejon.2005.03.013.

Lemieux, L., Kaiser, S., Pereira, J., Meadows, L.M., 2004. Sexuality in palliative care: patient perspectives. Palliative Medicine 7, 630-637.

Maughan, K., Clarke, C., 2001. The effect of a clinical nurse specialist in gynaecological oncology on quality of life and sexuality. Journal of Clinical Nursing 2, 221-229.

Nakopoulou, E., Papaharitou, S., Hatzichristou, D., 2009. Patients' sexual health: a qualitative research approach on Greek nurses' perceptions. Journal of Sexual Medicine 8, 2124-2132. http://dx.doi.org/10.1111/j.1743-6109.2009.01334.x.

Nicolai, M.P., Both, S., Liem, S.S., Pelger, R.C., Putter, H., Schalij, M.J., et al., 2013. Discussing sexual function in the cardiology practice. Clinical Research in Cardiology. http://dx.doi.org/10.1007/s00392-013-0549-2.

Olsson, C., Berglund, A.L., Larsson, M., Athlin, E., 2012. Patient's sexuality - a neglected area of cancer nursing? European Journal of Oncology Nursing 4 426-431. http://dx.doi.org/10.1016/j.ejon.2011.10.003.

Oskay, U., Can, G., Basgol, S., 2014. Discussing sexuality with cancer patients: oncology nurses attitudes and views. Asian Pacific Journal of Cancer Prevention 17, 7321-7326.

Reynolds, K.E., Magnan, M.A., 2005. Nursing attitudes and beliefs toward human sexuality: collaborative research promoting evidence-based practice. Clinical Nurse Specialist 5, 255-259.

Sadovsky, R., Basson, R., Krychman, M., Morales, A.M., Schover, L., Wang, R., et al., 2010. Cancer and sexual problems. Journal of Sexual Medicine 1 (2), 349-373. http://dx.doi.org/10.1111/j.1743-6109.2009.01620.x.

Saunamaki, N., Andersson, M., Engstrom, M., 2010. Discussing sexuality with patients: nurses' attitudes and beliefs. Journal of Advanced Nursing 6, 1308-1316. http://dx.doi.org/10.1111/j.1365-2648.2010.05260.x.

Silman, A.J., MacFarlane, G.J., 2002. Epidemiological Studies. A Practical Guide, second ed. Cambridge University Press, Cambridge.

Stead, M.L., Brown, J.M., Fallowfield, L., Selby, P., 2003. Lack of communication between healthcare professionals and women with ovarian cancer about sexual issues. British Journal of Cancer 5, 666-671. http://dx.doi.org/10.1038/ sj.bjc.6600799.

Valencius, J.C., Packard, R., Widiss, T., 1980. The ONS-ANA outcome standards for cancer nursing practice: two models for implementation. II. Implementation of the nutrition standard at City of Hope National Medical Center. Oncology Nursing Forum 3, 37-40.

White, I.D., Allan, H., Faithfull, S., 2011. Assessment of treatment-induced female sexual morbidity in oncology: is this a part of routine medical follow-up after radical pelvic radiotherapy? British Journal of Cancer 7, 903-910. http:// dx.doi.org/10.1038/bjc.2011.339.

World Health Organization, 2006. Defining Sexual Health: Report of a Technical Consultation on Sexual Health, 28-31 January 2002, Geneva. World Health Organization, Geneva.

Wright, E.P., Kiely, M.A., Lynch, P., Cull, A., Selby, P.J., 2002. Social problems in oncology. British Journal of Cancer 10, 1099-1104. http://dx.doi.org/10.1038/ sj.bjc.6600642.

Zeng, Y.C., Li, Q., Wang, N., Ching, S.S., Loke, A.Y., 2011. Chinese nurses' attitudes and beliefs toward sexuality care in cancer patients. Cancer Nursing 2, E14-E20. http://dx.doi.org/10.1097/NCC.0b013e3181f04b02. 